\title{
Values and Educative Aspirations
}

\author{
Héctor Gabriel Zazueta Beltrán, José Carlos Pardini Moss \\ Universidad Autónoma de Sinaloa, Culiacán Rosales, México
}

\begin{abstract}
Empirical research was done interviewing face to face a sample of 2,447, 10-12 grade students in Culiacan, Sinaloa, Mexico, from the main public university high school in town. Education is seen as a tool to develop better citizens first, and better workers later. The objective of this research was to detect different perceptions related to values and education. Using a 13 items questionnaire, we measured: Students’ perceptions about him/herself as part of their education role, responsibility that students show toward activities in school, perceptions about education as a tool to grow in the social ladder and as a way of social recognition, social perception about effort as an important value to self-improve and get social recognition, and to finish, perceptions about their teacher's performance.
\end{abstract}

Keywords: values, meaning of education, education reference models

\section{Problem}

On one hand, values are solid beliefs, expressed generally by pairs of antagonistic words. That is, by individual preferential election, values govern as guides of individual and groups behavior, which are ordered hierarchically following the context of the situation in which they are, evaluated from very important to nothing important (Zazueta-Beltrán, 2007 as listed in Zazueta \& Arciniega, 2010). On the other hand, Rokeach (1973) maintains that values do not remain static but they are ranked differently in the diverse aspects of life.

High school students from the State of Sinaloa, Mexico, receive, especially, a social influence of groups that show economic power, acquired presumably from illicit activities. This, coupled with other situations of student life, might influence the way they rank their values and their perception on the meaning of education (e.g., mechanism of self-improvement in a social system). Pressured by an evidently materialistic culture, high school students could be losing interest to be educated. Additionally, it can be perceived that students are lacking moral direction while not having good role models that guide them through life. Due to diverse social and economic factors, it becomes harder for teachers to play their role of introducing certain values to young people, to inspire students so that they perceive education as an option on personal and professional self-improvement. High school teachers interact with their students between 3 and 5 hours per week, which offers them opportunity to have an influence in the student values. Nevertheless, it is important to ask, are teachers respected and mirrored by students, considering perception of the students as the basis of this decision. Do teachers show a behavior that expresses values recognized as good within the social moral lived in the place they work?

Students in Sinaloa and other regions of Mexico and all over the world are coexisting in a society that, by means

Héctor Gabriel Zazueta Beltrán, Ph.D. in business administration, Universidad Autónoma de Sinaloa. José Carlos Pardini Moss, Ph.D. in human development, Universidad Autónoma de Sinaloa. 
of the excessive use of mass media, are pressured to rearrange their values. Reasons why, in agreement with Rokeach (1973, p. 5) and Morris (1957), a person not only prefers a particular form or final state of existence when compares it with the opposite side, but also compares it with other values that are within a system of values. Also, Morris (1957) maintains that since the individual can consider more of a highly important value, it can be possible to establish a measurement of psychological distance between these values, of such form that is inferred that a person who selected a value can be very temped to choose the second, or the third one, and so on. Naturally, due to the biological development of adolescence, a young student is in constant self-conflict. It is in this stage where the human being begins to form its personal identity and to dream up the character that will define him or her as an adult.

High school students' perception about having few options of self-improvement to scale social steps, to be accepted, and to be recognized is influencing them to lost interest in education. As Davenport (2000) mentioned, making reference to the company like social system: An organization who grants medals and prizes until everybody has three hanging by the wall of the office, can reduce recognition to a mere mechanical transaction. Perhaps to have a university degree is not enough to obtain genuine recognition of social moral. This may be a reason why many high school students might possibly be turning towards other models of influence-models that society recognizes and admires. In another words, they wish to imitate people who are not distinguished by their academic preparation.

The most listed reason on differences and similarities in values is that they are influenced by personal experiences and the exhibition to forces of formal socialization (Rockeach, 1973). For this reason, it is not surprising that many theoreticians see the values like products of a culture or social system. In another words, individuals learn through formal routes of socialization instead of informal routes of socialization. In the case of life values, this process generally happens in early life. For organization values, the process is carried out first, during the early days that the individual arrives at the social system, and it is reaffirmed during the time that the individual remains in this system (Meglino \& Ravlin, 1998). From the reflections raised by Meglino and Ravlin (1998), it is deduced that high school teachers have the opportunity to socialize certain values to their students since social interactions between student-teacher of the referred educational level are a minimum of three years for Mexico. Additionally, Davenport (2000) indicates that the daily conducts within an organization follow only the values that are compensated. Also, Garcia and Dolan (1997) maintained that if a professional yield of high quality is desired, the qualitative factors or values like confidence, creativity, honesty and beauty are highly important, more than the traditional economic quantitative concepts. It is very possible that values such as dishonorable work, corruption and the lack of appetite to strive might be values considered normal by high school students, since they are witnesses of how people who lack academic preparation occupy positions of popular election or jobs by nepotism. This is a serious problem for any immersed society in the heat of the 21st century where values like honesty, transparency and productivity are important to emphasize continuously in a more competitive world.

Finally, it is known that societies require direction, and values serve as elements that unify social behavior. Society's ethical system can be seen in its possession of values, expressed like principles that help to invoke, interpret, and orient social conduct (in another words, the one that has meaning and relevance for the others) and to judge it in degrees of good or bad (Singer, 1995). Based on that, and in agreement with the observable reality, it would be possible to conceive that in Sinaloa, high school students might be in constant psychological conflict at the time of deciding what to do with their life. High school students might be receiving incongruous messages of morality since on the one hand, the society tells them: "Study and self-improve and you will be a good citizen", 
but another voice (sometimes the same) might whisper: "It is not important to study, the important thing is to have material possessions so people respects, recognizes, and receives you well anywhere”.

\section{Methodology}

A survey with 13 questions was created to evaluate: (1) responsibility students have against their formal current education, (2) perception of education as a self-improvement tool and recognition in social scale, (3) social perception of the effort as a value directed towards self-improvement and recognition in social scale and (4) perceptions related to the professor's job. Answers were placed in the right part with Likert scale using five anchors where: 1 = In agreement, 0.75 = Little in agreement, $0.50=$ Neither in agreement nor in disagreement, $0.25=$ Little in disagreement and $0=$ In disagreement. Three senior high school students from the Universidad Autónoma de Sinaloa, Mexico were chosen to help conducting the interviews. Randomly, a face to face interview of 2,447 students was performed in the classrooms, covering students of all high school levels. The interviewed sample was integrated by $55.11 \%$ women and $44.89 \%$ men. In relation to age, the sample was integrated by $1.76 \%$ of less than 15 years old, $85.66 \%$ between 15 and 17 years old, and $12.58 \%$ greater than 17 years old.

\section{Results}

Results of this research are approached evaluating each one of the hypothesis that were considered:

$\mathrm{H}_{1}$ : Values like discipline, effort and respect have little importance on social moral while allocating recognition within social status.

With the objective to know the assessment that social moral gives to values like discipline, effort and respect, the following items were placed in the survey:

G: "I think that people who strive gets successful in life."

Men responded with an average of 0.890 (“in agreement”) and women marked 0.930 (“in agreement”). As it can be seen, women agreed the most with this question.

H: "I think that a lot of people get successful because he/she has good personal relationships."

Men responded little with an average of 0.711 ("in agreement") and women marked 0.653 ("little in agreement”). In this case, men agreed the most.

I: "Presently, people respect you only if you have money, without concerning its origin."

Men responded with an average of 0.697 (“in agreement”) and women marked 0.641 (“little in agreement”). As in the question before, men agreed the most as well.

Based on the answers of the previous items, it is observed that students are moderately in agreement that people who strives more are the one who gets successful in life, whereas on the other hand they are moderately in agreement that personal relationships are important to get successful, and they are moderately in agreement that social respect is obtained according to the amount of money the person manages or accumulates without concerning its origin. Therefore, due to these contradictions, there are not enough elements to say that hypothesis $\mathrm{H}_{1}$ is accepted.

$\mathrm{H}_{2}$ : Education is of little importance for high school students.

With the objective to know the meaning and social importance of education, the following items were considered: 
E: "For the majority of people, it is worth more to have money than to study."

Men marked an average of 0.726 (“in agreement”) and women 0.652 ("little in agreement”). Men agreed more with this sentence, compared to women's answer.

F: "I consider that if I study and make an effort, I can improve myself and get to be somebody in life."

Men marked an average of 0.935 (“in agreement”) and women 0.975 ("in agreement”). Women strongly agreed with this item.

L: "People respect you if you have a college degree."

Men marked an average of 0.704 ("in agreement") and women marked 0.684 ("little in agreement"). Interestingly, women were not convinced the most with this question.

Analyzing the answers given to the previous items, on the one hand it is observed that the answer to item $\mathrm{F}$ is the one that positions education strongly as an option of self-improvement within the social status; whereas on the other hand, it is observed that aspects like money are better positioned than education in the social moral (E) and that to study does not assure respect and recognition by that social moral (L). Therefore $\mathrm{H}_{2}$ is accepted. This is worrisome because if a value is measured by the importance an education degree has for the individual, it is possible to indicate that in Sinaloa, it is of little value to be educated, the reason why the student could be considering other activities as development options in the social status ladder, and this should indeed not be allowed.

$\mathrm{H}_{3}$ : Values like discipline, effort and responsibility have little importance to obtain high school students' goals.

With the object to identify if students are practicing some important values like discipline, effort and respect, the following items were considered:

A: "I make a great effort to study and get the best available grades in my tests."

Men responded with an average of 0.802 (“in agreement”) and women marked 0.835 ("little in agreement). In this case, women agreed the most.

B: "I am very responsible with school homework and activities"

Men responded with an average of 0.712 (“in agreement”) and women marked 0.790 (“little in agreement”). Again, women agreed the most.

C: "When I have exams I stay at home and study subject by subject"

Men responded with a 0.648 average ("little in agreement”) and women marked 0.716 ("little in agreement"). One more time, women agreed the most with this item.

K: "Presently I study hard and make my best effort because I want to improve myself and be somebody in life."

Men responded with an average of 0.808 (“in agreement”) and women marked 0.867 (“little in agreement”). Women, again, agreed the most.

With the objective to observe correlations between items related to discipline, effort and responsibility, the following table was developed.

In Table 1, it is showed that students have clarity about importance to be disciplined, maintain an effort and be responsible in school tasks if they want to get good grades and see education as something important in life. Nevertheless, while observing item answers B, C and K, they are not as clear as to say that students show a congruent conduct with their values. Here, it is observed an obvious conflict of values; in agreement with Morris (1957) students could know the conducts they should observe if they want to be good according to social moral, however, it is not congruent with their conduct. According to Morris (1957) individual chooses first the most 
important value followed by the less important. Based on this, it could be inferred that in fact students practice values like discipline, effort and responsibility. Therefore, $\mathrm{H}_{3}$ is accepted. It is pertinent to comment that, in this situation social moral's little importance could have influenced the education variable (which was manifested with the acceptance of $\mathrm{H}_{2}$ ). Nevertheless, the last phenomenon does not mean that students are totally undisciplined, sluggish or irresponsible, in agreement with some investigators (Schwartz, 1999; Rokeach, 1973) who sustain that values are ordered hierarchically following the context and or situation in which individuals are. Additionally, values can be changed using interventions that produce self-dissatisfaction (Rokeach \& Ball-Rokeach, 1989; Schein, 1985).

Table 1

Correlations Between Items Related to Discipline, Effort and Responsibility

\begin{tabular}{lllll}
\hline & A & B & C & K \\
\hline A: Make a great effort to study to get the best grades & & $0.461^{* *}$ & $0.441^{* *}$ & $0.444^{* *}$ \\
B: Very responsible with school homework and activities & $0.461^{* *}$ & & $0.422^{* *}$ & $0.376^{* *}$ \\
C: When tests, stay at home to study subject by subject & $0.441^{* *}$ & $0.422^{* *}$ & & $0.385^{* *}$ \\
K: Study hard because wants self-improvement & $0.444^{* *}$ & $0.376^{* *}$ & $0.385^{* *}$ & \\
\hline
\end{tabular}

Note. According to Pearson correlation (**) it means $p<0.01$.

$\mathrm{H}_{4}$ : Teachers' image is poor and they are poorly mirrored by their students.

Additionally, to find out the perception about teachers and their job, considering respect and admiration deserved by their students, the following items were asked:

D: "I consider that the majority of my friends respect teachers."

Men responded with an average of 0.494 (“nor in agreement nor in disagreement”) and women marked 0.548 ("nor in agreement nor in disagreement"). Although both are not good scores, women agreed the most with this item.

J: "Most of my teachers are lazy and they do not prepare well their classes."

Men responded with a 0.456 average ("neither in agreement nor in disagreement") and women marked 0.419 (“nor in agreement nor in disagreement”). Men agreed the most with this item.

M: "Most of my teachers are very hard workers and prepare very well their classes."

Men responded with an average of 0.671 ("little in agreement”) and women marked 0.698 ("in agreement”), being with greater intensity the answers from women.

Therefore, sustained by the previous results, it is considered that $\mathrm{H}_{4}$ is accepted.

Using arithmetical formula it was obtained on the one hand the percentage of teachers who deserve students' respect by the professionalism and responsibility they show at work; and on the other hand the percentage of teachers who students admire. $58.11 \%$ of men think that teachers deserve respect and $61.91 \%$ of women respect their current teachers. Also, results showed that $29.58 \%$ of men admire the teachers that at the time of this survey are teaching them, whereas $30.10 \%$ of women do so (see Table 2).

$\mathrm{H}_{5}$ : High school students are influenced mainly by negative news of mass media instead of by the classes of their teachers.

With the objective to measure penetration levels that teachers' classes have in students' minds, three important historical figures were put to be ordered according to students' historical perception. In the following 
Table 3, percentage of men and women who recognized the individuals' contribution and influence in Mexico's national history is observed.

Table 2

Students' Perception About Teachers as a Model of Reference to be Mirrored

\begin{tabular}{lll}
\hline Respect and admiration for current teachers & Men (\%) & Women (\%) \\
\hline Teachers who deserve respect & 58.11 & 61.91 \\
Admired teachers & 29.58 & 30.10 \\
\hline
\end{tabular}

Table 3

Percentage of Men and Women Who Identified Relevant National Individuals

Principio del formulario

National individuals identified for sample

Final del formulario

\begin{tabular}{lll}
\hline National figure & Men (\%) & Women (\%) \\
\hline Emiliano Zapata & 71.9 & 78.2 \\
Lázaro Cárdenas & 43 & 47 \\
José Ma. Morelos & 63.4 & 73.3 \\
\hline
\end{tabular}

On one hand, one objective was to value the impact and influence that massive means of communication have in students' minds when crowding them with negative news, dedicating ample spaces to describe violent facts and informing them about presumed delinquents. Three names of presumed drug dealers mentioned by the press were included, and it was requested that they write the activity to which they related these individuals to. $83.43 \%$ of men located activity related with the three names mentioned, whereas $92.2 \%$ of women recognized the activity to whom supposedly the individuals are involved in, according to the news. It is observed that women marked higher than men. This situation could be explained with different arguments, mentioning the following two: (1) women have better memory than men (since they remembered in a greater proportion than men, as much the national figures, as the presumed drug dealers) or (2) women mainly are influenced by the social phenomenon to see a "possible wedding" with a drug dealer as an option of scaling steps in a society oriented to grant greater social recognition to people who has greater economic level. Based in the previous results, it is considered that $\mathrm{H}_{5}$ is accepted.

\section{Conclusions}

Based on a high school students sample from Sinaloa, Mexico, values like discipline, effort and responsibility are little practiced. This could be influenced by the little importance and recognition that the social moral grants to these values, as well as because of the meaning that education has for the same social moral, and the recognition for individuals who are educated. If students do not practice values like discipline, effort and responsibility at school, it is possible that their future work establishments could have problems, and those values are highly important to achieve the companies' goals. Teachers are respected but have little influence as reference models to be mirrored by their students. Elements like reduction of benefits and low wages seem to allow individuals without suitable preparation or professional vocation to play one of the most important social roles, as it is to educate citizens. Also, reduced wages places teachers in the lowest part of the social ladder within a society evidently oriented towards the material, which influences students to have poor perceptions of their teachers. Finally, possible corruption and poor ethical behavior of some teachers as well as the degradation of teachers' job could be influencing the students. High 
school students are harassed by mass media like television, newspapers and Internet. Drug trafficking as a social problem could influence students' educative aspirations due to the moral corruption of a society that seems to value people more based on appearance and possessions than on wisdom and culture.

\section{Limitations}

Following are the limitations of this research:

(1) Percentage of respected and admired teachers was obtained depending on their professionalism and responsibility at their work place, based on their students' perceptions; however, an item reflecting conducts that reduce respect and admiration of teachers was not asked.

(2) Practice of discipline, effort and responsibility to obtain the school goals of students was evaluated by self-perception; students could have been dishonest with themselves. Teachers were not asked on the practices of their students' values.

(3) Excessive space that grants mass media to violent news related to drug trafficking, places teachers in disadvantaged to fulfill the task of positioning the historical national individuals in the mind of the students.

(4) This study was done in Culiacan, Sinaloa, one of the most violent cities in Mexico. The culture of this region could be a variable that influences our research results.

\section{Epilogue}

It is evident that against this moral decomposition, education is losing its battle and teachers almost declare themselves incapable to stop this avalanche that seems to annihilate us. In the work environment, a similar future is prognosticated, since current students will be workers in the upcoming years. This type of society has been already foretold by Schlemenson (1990), when indicating that progressive loss of values contributes to the decay of social moral.

\section{References}

Abu-Saad, I., \& Isralowitz, R. E. (1997). Gender as a determinant of work values among university students in Israel. Journal of Social Psychology, 137(6).

Allport, F. H. (1924). Social psychology. New York: Houghton Mifflin.

Davenport, T. O. (2000). Human capital. Barcelona, Spain: Ediciones Gestión.

Elizur, D. (1994). Gender and work values: A comparative analysis. Journal of Social Psychology, 134(2).

García, S., \& Dolan, S. L. (1997). Managing by values. Madrid, España: McGraw-Hill /interamericana de España, S.A.U

Meglino, B., \& Ravlin, E. (1998). Individual values in organizations: Concepts, controversies and research. Journal of Management, 24(3).

Morris, R. (1957). Occupations and values. Glencoe, Illinois: Free Press.

Rokeach, M. (1973). The nature of human values. New York: The Free Press.

Rokeach, M., \& Ball-Rokeach, S. (1989). Stability and change in American values, 1969-1981. American Psychologist, 44, $775-784$.

Schein, E. H. (1985). Organizational culture and leadership. San Francisco, CA: Jossey-Bass.

Schlemenson, A. (1990). Ehtic percpective in an organization analysis: A reflexive commitment with action. Paidós, Argentina.

Schwartz, S. H. (1999). A theory of cultural values and some implications for work. Applied Psychology, 48(1), 23-55.

Singer, P. (1995). Compendium of Ethics. Alianza.

Zazueta-Beltrán, H. G. (2007). Incongruence between individual values and organizational values and its relation with intentions of absenteeism and labor abandonment: The case restoration industry of Sinaloa, Mexico (Doctoral Thesis, Faculty of Economic and Administrative Sciences, University of Barcelona, Spain).

Zazueta-Beltrán, H. G., \& Arciniega, L. (2010). Development of job values. México: Trillas Editorial. 